\title{
To Study Weld Strength and Strain Energy Absorption of Roll Over Protection Structure of an All Terrain Vehicle.
}

\author{
Saini Amandeep Singh ${ }^{1}$ \\ ${ }^{I}$ (B. Tech., Mechanical Engineering, U. V. Patel College of Engineering, Gujarat, India)
}

\begin{abstract}
The roll over protection structure, referred as ROPS is designed to protect the driver from the injuries caused by roll-overs. In addition to safety against roll-overs and collisions, it also acts as a single rugged base for mounting the sub-systems of the all terrain vehicle. This study will deals with edge preparation techniques employed prior to welding to strengthen the ROPS and corresponding strain energy absorption at the time of collision. The design of ROPS depends on the vehicle size, weight distribution, sub-system mounting, occupant's safety and ergonomics; followed by force analysis under specified crash conditions.
\end{abstract}

Keywords: Analysis, Comparison, Edge-Preparation, Roll-over Protection Structure, Welding.

\section{INTRODUCTION}

The roll-over protection structure ${ }^{[1][2][3]}$ is a specially engineered and constructed frame built in or around the passenger compartment of a vehicle to protect its occupants from being injured in an accident, particularly in the event of a roll-over. In addition to provision of safety, the ROPS also acts as a single rugged base for mounting various sub-systems of the vehicle. It also helps to stiffen the vehicle under various collisions, which is desirable in racing and off-road applications.

There are different ROPS designs depending on the application, hence the vehicle manufacturers have differing specifications and regulations. The design of roll cage is based upon criteria like vehicle size, weight distribution, sub-system mounting, occupant safety and ergonomics, followed by force analysis under various crash conditions. For the manufacture of ROPS, the hollow circular tubes are highly preferred over squared tubes due to higher comparative bending strength and ease of fabrication. The material of tubes is selected by considering various aspects such as yield strength, bending strength, density and cost. Some of the examples are mild steel, drawn-over-mandrel steel \& chrome-alloy steel.

The study of this research paper will deals with the simulations done to determine the weld strength and the strain energy absorption of the ROPS at the time of collision. The different edge preparations for the ROPS pipe subjected to welding is considered under the static analysis. The main aim is to reduce the stress concentration and to absorb maximum of the strain energy which will ultimately renders a higher resilient material. The analysis is done in ANSYS 14.0 Workbench.

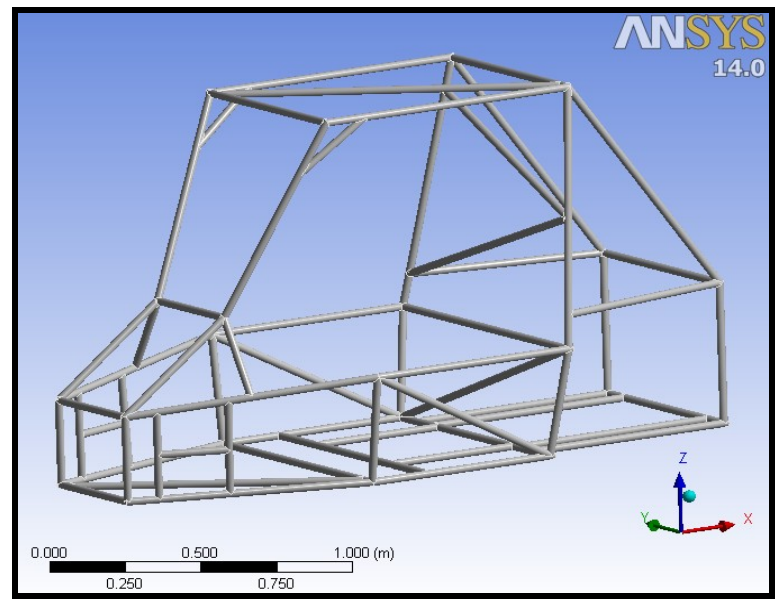

Figure 1. Roll Over Protective Structure

II.

SimULATION

The structural analysis is performed in order to determine the effect of the loads and forces on the ROPS under consideration. The ROPS is subjected to different loading conditions like front impact, rear impact, side impact and roll-over. 


\subsection{Material and Welding Technique.}

The material used for fabricating the ROPS is AISI 4130 as it is more responsive to mechanical and heat treatment than the carbon steels. AISI 4130 alloy steel contains chromium and molybdenum as strengthening agents. It has low carbon content, and hence it can be welded easily. The material properties ${ }^{[4][5]}$ are shown in Table-1

Table 1. Material Properties AISI 4130

\begin{tabular}{|l|l|}
\hline \multicolumn{2}{|c|}{ Chemical Property } \\
\hline Element & Content(\%) \\
\hline Iron, Fe & $97.03-98.22$ \\
\hline Chromium, Cr & $0.80-1.10$ \\
\hline Manganese, Mn & $0.4-0.6$ \\
\hline Carbon, C Physical Properties \\
\hline Molybdenum, Mo & $0.28-0.33$ \\
\hline \multicolumn{2}{|c|}{ Mechanical Properties } \\
\hline Density & $7.85 \mathrm{~g} / \mathrm{cm}^{3}$ \\
\hline Melting Point & $1432 \mathrm{C}$ \\
\hline \multicolumn{2}{|c|}{$655.0 \mathrm{MPa}$} \\
\hline Tensile strength, ultimate & $517.0 \mathrm{MPa}$ \\
\hline Tensile strength, yield & $190-210 \mathrm{MPa}$ \\
\hline Modulus of elasticity & 0.3 \\
\hline Poisson Ratio & $42.7 \mathrm{~W} / \mathrm{mK}$ \\
\hline \multicolumn{2}{|c|}{ Thermal Properties } \\
\hline Thermal Conductivity (100 C)
\end{tabular}

The welding electrode used is ER $80 \mathrm{~S}-\mathrm{G}$. with minimum tensile strength of $550 \mathrm{MPa}$ and maximum $635 \mathrm{MPa}$. TIG welding is considered for performing this operation.

\subsection{Calculation of loading condition.}

The impact tests are intended to represent the most frequent type of road crash, resulting in serious or fatal injury. The calculation of impact forces during various collisions is done in following manner:

The change in the kinetic energy of an object is equal to the net work done on the object. This fact is referred to as the Work-Energy principle and is often a very useful tool in mechanics problem solving. According to the work-energy principle ${ }^{[6]}$,

$$
\mathrm{W}_{\text {net }}=\frac{1}{2} \mathrm{~m} \times \mathrm{V}^{2} \text { final }-\frac{1}{2} \mathrm{~m} \times \mathrm{V}^{2} \text { initial }
$$

It is derivable from conservation of energy and the application of the relationships for work and energy, so it is not independent of the conservation laws. For a straight-line collision, the net work done is equal to the average force of impact times the distance travelled during the impact.

(Average impact force $) \times($ distance travelled $)=$ change in kinetic energy

Considering mass of the all terrain vehicle, $\mathrm{m}=270 \mathrm{~kg}$

Velocity of all terrain vehicle, $V=60 \mathrm{~km} / \mathrm{h}=16.67 \mathrm{~m} / \mathrm{s}$

Distance at which vehicle stops after crash, $\mathrm{d}=1 \mathrm{ft}=0.3048 \mathrm{~m}$

Then average impact force,

$$
F_{\text {avg }}=\frac{\mathrm{m} \times \mathrm{V}^{2}}{2 \times \mathrm{d}}=123.031 \times 10^{3} \mathrm{~N}
$$




\subsection{Loading constraint and loading condition}

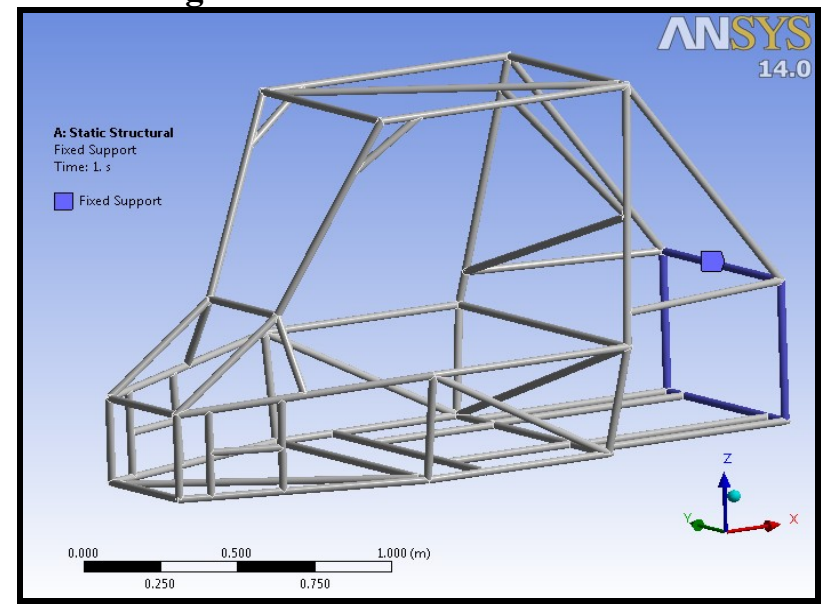

Figure 2. Impact loading constraint.

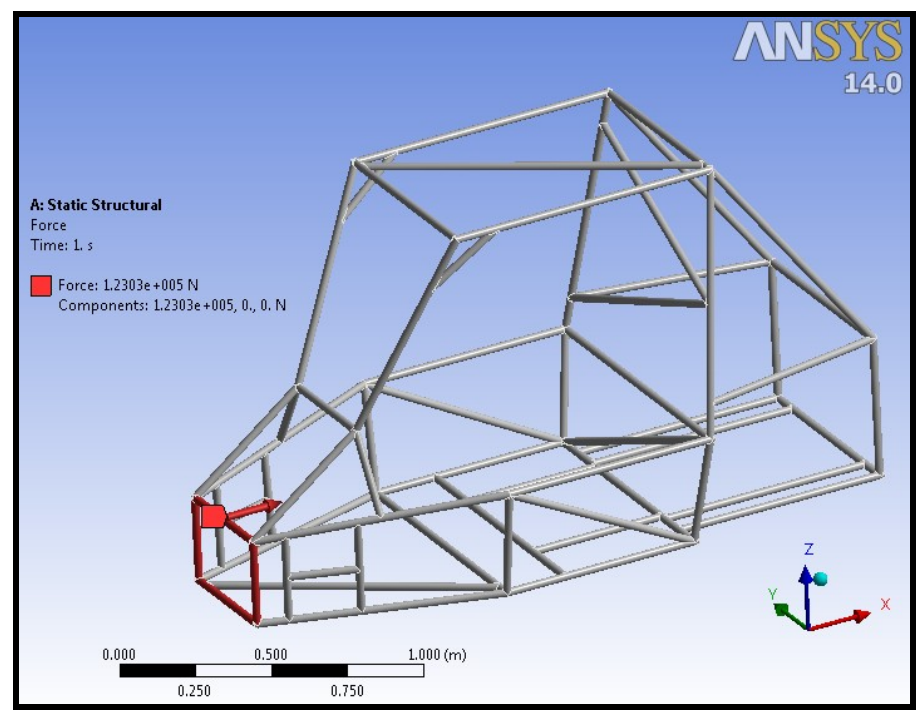

Figure 3. Impact loading condition

\subsection{Edge Preparation}

The experiment to be performed will be scrutinized considering different edge preparations i.e. the welding of pipes at the joints will be performed with no space groove preparation, with $2.5 \mathrm{~mm}$ space groove preparation and $5.0 \mathrm{~mm}$ space groove preparation. After performing the analysis, the strength of the weld is comparaed against all the considered cases. Also the strain energy absorbed in each case is investigated. Obviously the one with lesser Von-Mises stress will be a better design.

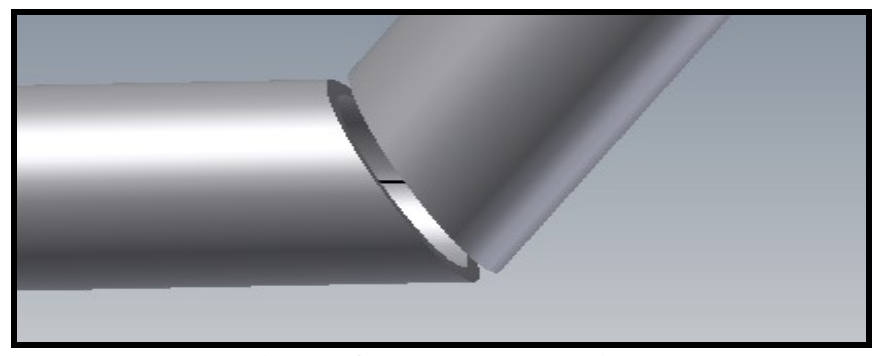

Figure 4. Edge Preparation

\subsection{Analysis}

The analysis of the roll over protection structure is done considereing the case of the front impact, rear impact, side impact and roll-over scenario of the all terrain vehicle. The typical values of the Von-Mises stress, deformation and the strain energy for all the above considered cases are compared against different edge 
To study weld strength and strain energy absorption of roll over protection structure of an all terrain vehicle.

preparations. The equivalent Von-Mises stress and Strain energy for front impact is shown in the figure 5 and figure 6 respectively.

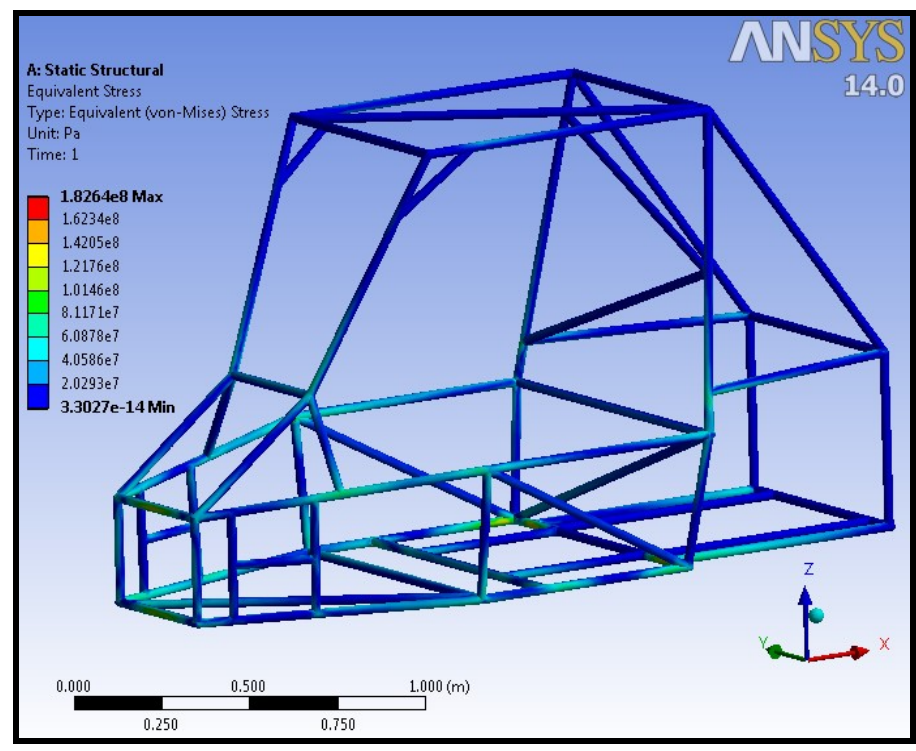

Figure 5. Equivalent Von-Mises Stress

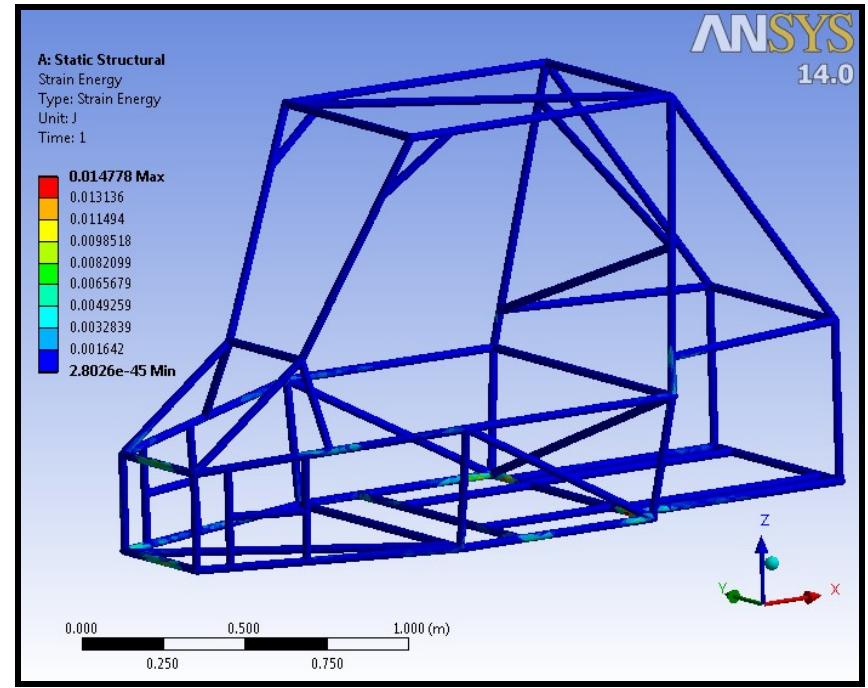

Figure 6. Strain Energy

\subsection{Comparison table.}

Table 2. Different Edge Preparation Analysis Results

\begin{tabular}{|c|c|c|c|}
\hline \multicolumn{4}{|c|}{ Roll Over Protection Structure (ROPS) } \\
\hline & No groove & $2.5 \mathrm{~mm}$ groove & $5 \mathrm{~mm}$ groove \\
\hline \multicolumn{4}{|c|}{ Front impact } \\
\hline Total deformation $(\mathrm{mm})$ & 2.569 & 3.5 & 4.2 \\
\hline Equivalent Von-Mises stress (MPa) & 182.64 & 195.36 & 201.21 \\
\hline Strain Energy absorbed $(\mathrm{kJ} / \mathrm{kg})$ & 14.79 & 17.62 & 19.48 \\
\hline \multicolumn{4}{|c|}{ Rear impact } \\
\hline Total deformation $(\mathrm{mm})$ & 5.39 & 7.23 & 8.97 \\
\hline Equivalent Von-Mises stress (MPa) & 215.72 & 228.07 & 237.28 \\
\hline Strain Energy absorbed $(\mathrm{kJ} / \mathrm{kg})$ & 23.75 & 27.43 & 30.05 \\
\hline \multicolumn{4}{|c|}{ Side impact } \\
\hline Total deformation $(\mathrm{mm})$ & 7.32 & 8.35 & 9.12 \\
\hline Equivalent Von-Mises stress (MPa) & 227.51 & 242.83 & 251.52 \\
\hline Strain Energy absorbed $(\mathrm{kJ} / \mathrm{kg})$ & 31.94 & 35.83 & 40.35 \\
\hline \multicolumn{4}{|c|}{ Roll over } \\
\hline Total deformation $(\mathrm{mm})$ & 4.46 & 5.06 & 5.92 \\
\hline Equivalent Von-Mises stress (MPa) & 204.31 & 222.42 & 241.73 \\
\hline Strain Energy absorbed $(\mathrm{kJ} / \mathrm{kg})$ & 21.76 & 28.63 & 35.21 \\
\hline
\end{tabular}


III.

CONCLUSION

From the simulation it can be concluded that, the ROPS with no space provided during groove preparation has lesser value for maximum Von-Mises stress concentration which thereby provides better protection and safety i.e. higher weld strength. The deformation during the collision increases correspondingly with the groove gap of the edge preparation. The strain energy absorption shows an upward trend parallel to the stress value.

\section{Acknowledgements}

I would like to thank Dr. Bhavesh P. Patel for his utmost support and encouragement. He kindly read my paper and offered invaluable detailed advices on grammar, organization, and the theme of the paper.

\section{References}

[1] A D Stockton, D H O'Neill and C J Hampson, Methods for optimizing the effectiveness of roll-over protective system by Silsoe Research Institute for the Health and Safety Executive ( Norwich NR3 1BQ, Crown Copyright, 2002).

[2] Thambiratnam, D. P. and Clark, B. J. and Perrera N. J., Performance of a roll over protective structure for a bulldozer. Journal of Engineering Mechanics,135(1), 2009, 31-40

[3] Thambiratnam, David P. and Clark, Brian J. and Perera Nimal J., Dynamic Response of a Rollover Protective Structure. ComputerAided Civil and Infrastructure Engineering, 23(6), 2008, 448-464.

[4] Joseph Lee Evins, Dependence Of Strength On Corrosion-Fatigue Resistance Of AISI 4130 Steel, Georgia Institute of Technology, Atlanta, 2004

[5] Catalogue of Material Properties of Alloys and Metals, Heng Tat Trading Co. Ltd., Hong Kong, China.

[6] Andrew Pytel and Jaan Kiusalaas, Engineering Mechanics-Dynamics (Stamford CT, USA: Cengage Learning Inc, 2010). 